\title{
Magnifying Endoscopy With Narrow Band Imaging and Endoscopic Ultrasonography for Assessing Eosinophilic Esophagitis
}

\author{
Bong Eun Lee and Gwang Ha Kim* \\ Department of Internal Medicine, Pusan National University School of Medicine, Busan, Korea
}

A 59-year-old man presented with epigastric pain during the past 4 weeks. Because his symptom was aggravated with ingestion of food, he complained of poor oral intake and weight loss of $4 \mathrm{~kg}$. His medical history included bronchial asthma which had been diagnosed 4 months before, but he took medicine irregularly. Physical examination was unremarkable. Laboratory studies showed peripheral eosinophilia $(920 / \mu \mathrm{L}, 14.5 \%$ of the circulating leukocytes), and an elevated immunoglobulin $\mathrm{E}$ level (895.2 IU/mL). Computed tomography of abdomen demonstrated diffuse thickening of the distal esophageal wall (Fig. 1). On upper endoscopy, the distal esophagus was edematous and pale with adherent pin point whitish exudates (Fig. 2A). Magnifying endoscopy with narrow band imaging demonstrated multiple white micronodules on the mucosal surface (Fig. 2B). Endoscopic ultrasonography (EUS) showed circumferential, mainly thickening of the deep mucosal/submucosal and inner circular muscle layers (Fig. 2C). We took biopsy specimens from proximal, middle and distal esophagus, and only biopsy from distal esophagus showed $>20$ eosinophils per high-power field infiltrating the esophageal mucosa (Fig. 3A). Before the histological diagnosis of eosinophilic esophagitis, we tried proton pump inhibitor twice daily for him. However, proton pump in- hibitor did not do any good, and finally the patient was diagnosed with eosinophilic esophagitis. Skin prick tests for inhalant and food allergens showed negative results. Treatment was initiated with orally administered fluticasone $500 \mu \mathrm{g} 3$ times a day. Epigastric pain improved rapidly. At 8 weeks after treatment, endo-

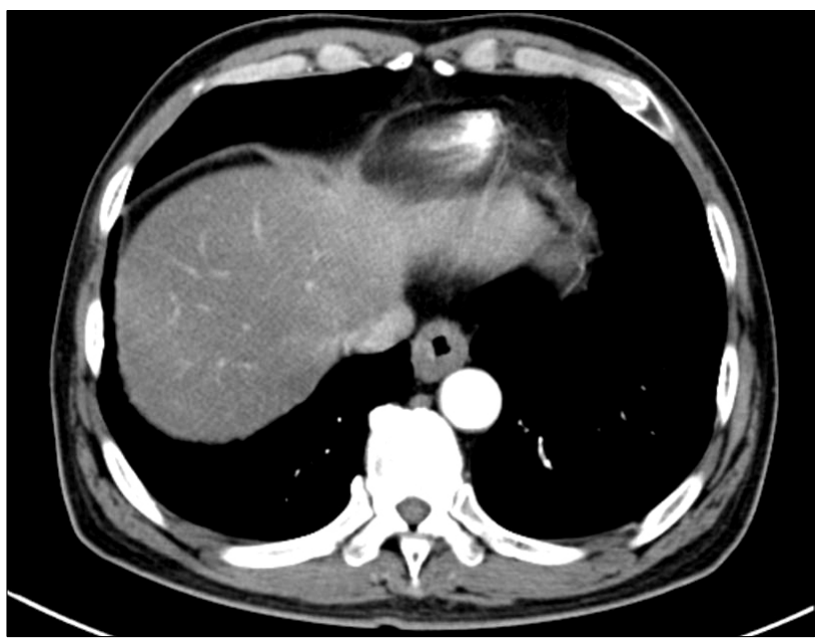

Figure 1. Computed tomography of abdomen demonstrates diffuse thickening of the distal esophageal wall.

Received: November 13, 2012 Revised: December 3, 2012 Accepted: December 11, 2012

(c) This is an Open Access article distributed under the terms of the Creative Commons Attribution Non-Commercial License (http://creativecommons. org/licenses/by-nc/3.0) which permits unrestricted non-commercial use, distribution, and reproduction in any medium, provided the original work is properly cited.

*Correspondence: Gwang Ha Kim, MD

Department of Internal Medicine, Pusan National University School of Medicine and Biomedical Research Institute, Pusan National University Hospital, 179, Gudeok-ro, Seo-gu, Busan 602-739, Korea

Tel: +82-51-240-7869, Fax: +82-51-244-8180, E-mail: doc0224@pusan.ac.kr

Financial support: None.

Conflicts of interest: None. 

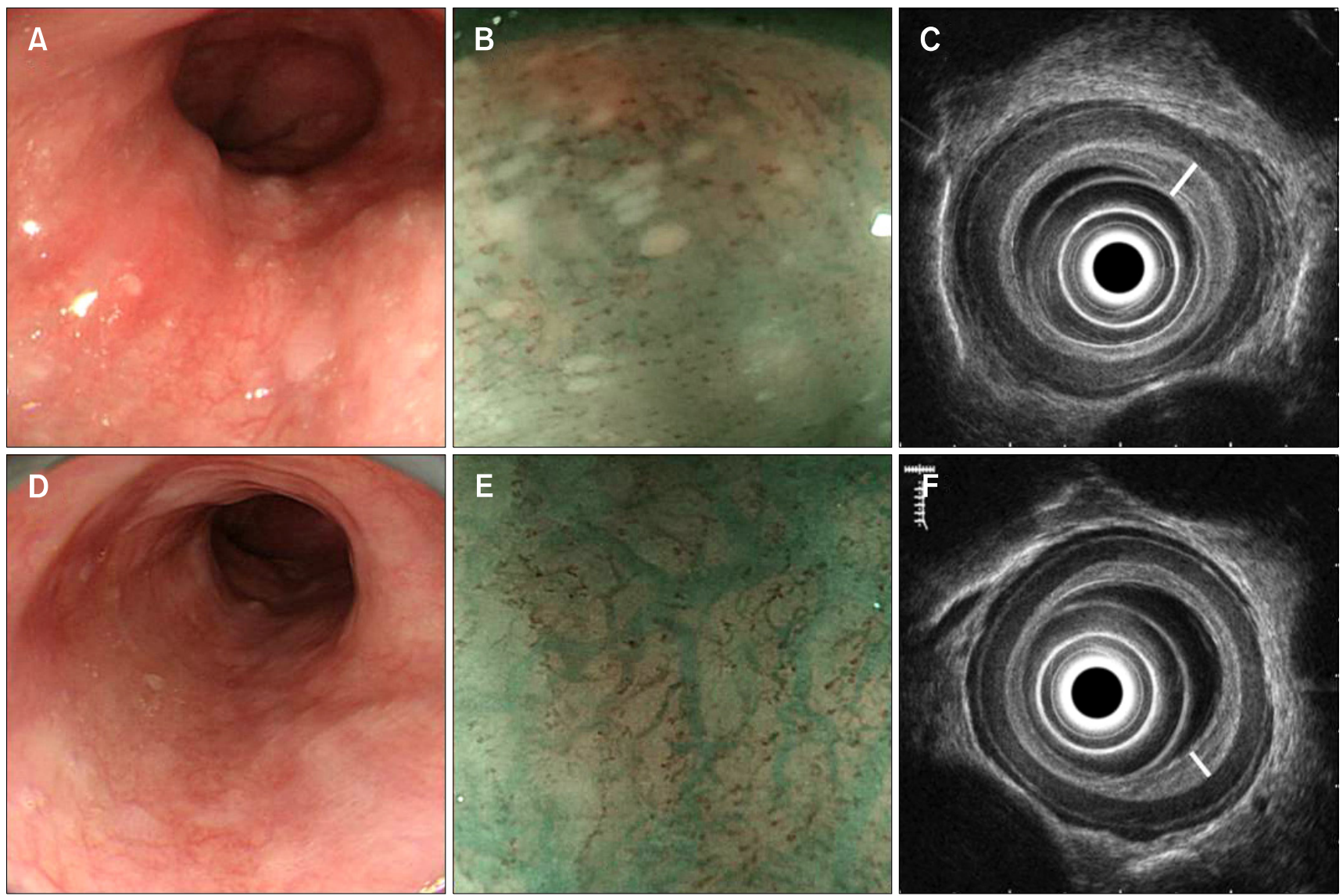

Figure 2. Endoscopic findings (A-C, before treatment; D-F, after treatment). (A) Upper endoscopy shows edematous and pale esophagus with adherent pin point whitish exudates. (B) On magnifying endoscopy with narrow band imaging, there are multiple white micronodules on the esophageal mucosal surface which correspond to eosinophilic microabscesses. (C) Endoscopic ultrasonography (EUS) demonstrates thickening of deep mucosal/submucosal and inner circular muscle layers (3.6 and $3.1 \mathrm{~mm}$, respectively). Scale bar $=1 \mathrm{~cm}$. (D) Mucosal edema improves and nearly normal esophagus is seen on conventional endoscopy. (E) White micronodules disppears and vascular structure is more clearly seen than before. (F) EUS shows decreased thickness of deep mucosal/submucosal and inner circular muscle layers $(2.8$ and $2.5 \mathrm{~mm}$, respectively). Scale bar $=1 \mathrm{~cm}$.

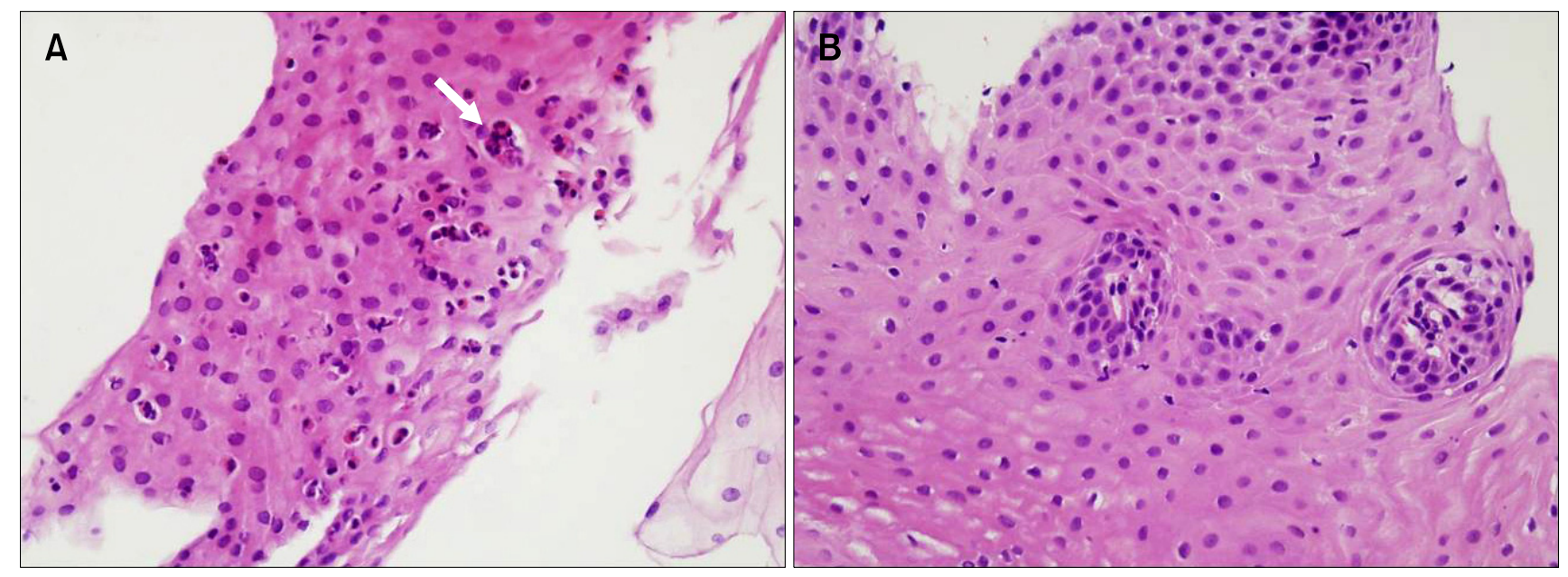

Figure 3. Histologic findings. (A) Biopsy specimen from the distal esophagus shows greater than 20 eosinophils per high power field infiltrating the esophageal mucosa associated with epithelial cell degeneration. And eosinophilic microabscesses (white arrow) are seen in the superficial portion of the squamous mucosa $(\mathrm{H} \& \mathrm{E}, \times 400)$. (B) After 8 -week treatment, histology reveals disappearance of the esosinophilic mucosal infiltration $(\mathrm{H} \& \mathrm{E}, \times 400)$. 
scopic features improved (Fig. 2D and 2E), and EUS showed decreased thickness of each layer of the esophagus (Fig. 2F). Histologic remission was also achieved (Fig. 3B). After 3 months of treatment with fluticasone, he stopped the medicine. At present, 6 months have passed without recurrence of symptom.

The roles of magnifying endoscopy with narrow band imaging and EUS for assessing eosinophilic esophagitis are not clear yet. ${ }^{1-3}$ However, looking at this case, those could be useful tools, especially when typical endoscopic features such as concentric rings and linear furrows are not seen by conventional endoscopy.

\section{References}

1. Furuta K, Adachi K, Kowari K, et al. A Japanese case of eosinophilic esophagitis. J Gastroenterol 2006;41:706-710.

2. Stevoff C, Rao S, Parsons W, Kahrilas PJ, Hirano I. EUS and histopathologic correlates in eosinophilic esophagitis. Gastrointest Endosc 2001;54:373-377.

3. Fox VL, Nurko S, Teitelbaum JE, Badizadegan K, Furuta GT. High-resolution EUS in children with eosinophilic "allergic" esophagitis. Gastrointest Endosc 2003;57:30-36 